\title{
"Changing the Game-Neighbourhood": An Energy Transition Board Game, Developed in a Co-Design Process: A Case Study
}

\author{
Mathias Lanezki *D, Catharina Siemer and Steffen Wehkamp \\ Department Energy, OFFIS e.V., Institute for Computer Science, 26121 Oldenburg, Germany; \\ catharina.siemer@offis.de (C.S.); steffen.wehkamp@offis.de (S.W.) \\ * Correspondence: mathias.lanezki@offis.de
}

Received: 5 October 2020; Accepted: 11 December 2020; Published: 15 December 2020

\begin{abstract}
Communicating knowledge about energy transition is a challenge of sustainable development. Serious games are a possible approach to explain complex relationships and present them to citizens. This paper discusses the development process of the serious board game "Changing the Game-Neighbourhood". Therefore, this paper describes our approach of developing a serious game with co-designers in four phases and illustrates the process using an example. Doing so, the paper focus on two central challenges: (1) How can a serious game be developed for the energy transition, which keeps a balance between learning and playability? (2) How can co-design contribute to the development of a serious game? We found out that the use of prototypes and the influence of different stakeholders as informants, co-designers, and testers were crucial for the expansion of the learning content, the improvement of the gameplay, and the balancing of the difficulty level. In addition, the energy transition at the neighborhood level appeared to be a suitable topic for a serious game. During the development process, the serious game was already used for citizen participation, involving about 120 participants in 15 workshops.
\end{abstract}

Keywords: serious games; energy transition; co-design; game prototyping; board game; smart city; smart neighborhood; participation

\section{Introduction}

Serious games are an interactive communication tool that can be used to reduce energy consumption in households [1,2], to improve education regarding sustainability [3] and green buildings [4], and to inspire students to work towards sustainability and energy savings [5]. Moreover, serious games are also well suited to illustrate and explain complex and abstract systems, for example, socio-hydrological theory and models [6], climate change [7], or urban issues [8]. Serious games can also be used to simulate real world situations and scenarios and to gain experience without real world consequences. They allow for experimenting, motivating one to reach goals, and promoting collaborative learning [9-12]. At the beginning of a game, complex mechanisms in the real world are simplified by a few, clear rules, which provide a framework for the execution of the game. Abstract concepts of the real world can be mapped into visible and tangible game mechanics to make them easier to explain. As the game progresses, players can move parts back and forth and see the effects directly. In board games, players keep the overview on the whole system because they have all individual parts in front of them at a glance. In the end, players have developed a whole variety of scenarios where they understand the trade-offs of different strategies.

One area of practical use for serious games is the energy transition. Saving energy and understanding the effects of renewable energy are important for sustainable development $[13,14]$. 
With its climate protection program 2030, the German government has set itself the goal to cover 65 percent of the nationwide electricity consumption with renewable energy by 2030 [15]. Concepts such as smart homes, smart grids, and smart districts as systems for networking and intelligent control of players in the energy industry gain importance as they bring energy production and consumption into harmony. Accordingly, they have a direct impact on our future way of life. To achieve the goals of the climate protection program, the energy supply needs to be changed. Implementation and use of new energy supply technologies by domestic users can help in this process. Citizens' awareness and understanding are the foundation for the acceptance of new technologies and for the conscious use of energy. Nevertheless, the topic of energy remains abstract, because energy is "untouchable" and "invisible" [16]. To increase the awareness, the acceptance, and understanding of citizens, effective ways of communication and participation are required.

Various approaches exist to provide knowledge about energy consumption for the consumer. For example: (1) Recommendations on how to save energy in combination with a descriptive normative message, e.g., how the majority of a citizens' neighbors perform in energy savings, can positively influence the behavior and lead to energy savings [17]. (2) Energy feedback can increase the awareness of the amount of energy consumption and can also lead to changes in consumption behavior [18]. It helps consumers to relate daily energy-consuming activities to the amount of energy they consume. Vine et al. [19] showed that energy savings of 5 to $20 \%$ can be achieved by visualizing energy consumption using smart meters and digital displays. They concluded that, besides other factors, energy feedback works best when the feedback is regularly delivered, interactive, and linked to a challenging goal of energy conservation. (3) The involvement of stakeholders as active co-designers and informants from the beginning of the development process of a user interface showed the relevance of participation in the topic of energy transition. The user interface "allows communication between the human as prosumer and the future energy network" [20]. Participation was given on the one hand in the interface itself and on the other hand in its development.

These examples usually refer to a household and a few concrete measures to save energy. If a combination of many different measures and technologies for energy transition is to be considered, the conventional types of energy feedback prove difficult, since the effects are often complex and can no longer be attributed to individual behavior. A different form of feedback on energy transition at a higher level is needed. A suitable method with crucial advantages is a serious game as a simulated form of energy feedback.

In order to provide knowledge about the energy transition in general and about our research project $(\mathrm{ENaQ}=$ Energetic Neighbourhood Quarter) in particular, we were looking for a communication and participation tool. As part of this research project, an old military site in Oldenburg, in North-East Germany, will be converted into a new residential area with a hybrid energy supply by the end of $2022[21,22]$. The primary objective of the ENaQ project is to develop a multisectoral, decentralized energy system with low $\mathrm{CO}_{2}$ emissions and a high proportion of electricity for own consumption, as well as guaranteeing the affordability of energy. Other essential elements are the evaluation of innovative energy technologies, digitalization, and a meaningful involvement of citizens. If possible, the overall concept developed in this project should then be transferable to other German residential areas. Due to its historical roots, the area is of great value to the citizens of Oldenburg and it is necessary to enable participation in the development process of the area. The foundation for this is an understanding of the processes that are planned as well as the energy system and its connection to one's daily life.

Participation formats can increase public acceptance of the planning procedures, and the technologies and measures of the energy transition [23]. The agency and self-efficacy experienced by the participants, e.g., in the form of simulated scenarios, discussions, involvement, and influence on decisions play an important role in this context. As mentioned before, serious games provide a useful way to convey abstract and complex content and could be part of public participation formats. In order 
to give people a broader look over an energy system and of their part in it, we decided to develop the serious game "Changing the Game-Neighbourhood".

Consequently, the serious game and the development process described in this paper are contributions to the Sustainable Development Goal number four "Qualitative Education". The Sustainable Development Goals were established by the United Nations General Assembly in 2015 and represent a set of 17 key global objectives "to achieve a better and more sustainable future for all" [24]. The game is intended to impart knowledge about energy transition technologies and measures for saving energy. In addition, it should provide knowledge about the sustainable use of resources, promote sustainable lifestyle, and motivate people to think more about topics related to energy transition. The target group of this serious game comprises all persons from the age of 16 who enjoy games, like to interact with other people, and want to experience new insights, regardless of whether they are interested in the field of energy transition and sustainability. The serious game is currently only available in German. All print materials are available for open source download on the project homepage [25].

"Changing the Game-Neighbourhood" describes the creation of a neighborhood and its energy system. In the final version of the game, the players try to achieve the goals of the German government for the energy transition in a cooperative way. These relate to a reduction in $\mathrm{CO}_{2}$ emissions and maximizing energy savings in the electricity, heating, and transport energy sectors. Various energy technologies and energy-saving measures are presented, which can be combined cleverly with each other. Many existing serious games in the field of energy deal either with the topic of energy saving in the household $[1,2,26-28]$ or the energy supply and climate impact of entire regions [7,29-32]. This serious game focuses on the neighborhood level to create a better connection to the everyday life and to develop the game at a local region. As a special feature of the game, the fluctuation of renewable energies is a core element of the game.

This paper focus on two central challenges: (1) How can a serious game be developed for the energy transition, which keeps a balance between learning and playability? (2) How can co-design contribute to the development of a serious game? Therefore, this paper describes our approach of developing a serious game with co-designers in four phases and illustrates the process using an example. This approach is explained using the example of the evolution of "Changing the Game-Neighbourhood". Section 2 describes the serious game after the initial concept phase and the development process in general. Section 3 presents the results of the three co-design phases. Section 4 describes the theoretical foundations of learning through playing, serious games in general, and co-design processes. The main findings are summarized and discussed in the conclusion in Section 5.

\section{The Serious Game: Changing the Game-Neighbourhood}

This section describes both the gameplay and game materials in the first prototype as well as the general iterative co-design development process of the game.

\subsection{Game Origin}

At the beginning of the development process, the original serious game "Changing the Game" [29] was tested in a group of seven people. The advantages and disadvantages of this serious game were discussed. The rough game mechanics and components such as playing cards, energy bricks, and game goals were retained. Two major modifications have been made to the original serious game. Firstly, the framework of the game was changed from European energy supply to a neighborhood energy supply. The observations of the co-developers and moderators of the original serious game showed that many players requested a regional version of "Changing the Game". In later tests, the game received positive feedback on this modification, because it provides a closer reference to everyday life. Smaller energy sizes, for example, are more manageable. A red energy brick now represents $30 \mathrm{car}$ tank fillings instead of the loading capacity of 10 supertankers. Energy systems such as photovoltaic systems on the roof and boilers in the basement are also easier to imagine than nuclear power plants and wind farms. The second major modification concerns the rebuilding of the electricity production 
tower. In this step, uncontrollable and controllable power plants were to be built to cover base and peak load. By removing this step, the overall game was simplified and shortened. As the fluctuation of renewable energies is no longer represented correctly, new mechanics were added in the next phase to reflect this property.

\subsection{Gameplay and Game Material}

In this phase, a first prototype was designed, which was tested and extended in the following co-design phases. The objective of Changing the Game-Neighbourhood is to fulfill the demands for electricity, heating, and transportation using a combination of renewable energy technologies and resources as well as energy saving behaviors, while minimizing environmental effects. The players are in the role of project managers who can cooperatively design the energy supply of a neighborhood according to their own standards. Information on the energy standard, i.e., energy consumption, $\mathrm{CO}_{2}$ emissions, and the share of renewable energies of a conventional new building settlement is provided. The players then set targets for their neighborhood, such as a target value for energy savings or $\mathrm{CO}_{2}$ savings, and try to achieve them by playing cards. The playing cards include technologies to generate, convert, and store energy, various mobility offers, or measures to save energy. These playing cards can be used to change the energy consumption, the way energy is produced, and the $\mathrm{CO}_{2}$ emissions of the neighborhood. At the end of the game, the players check if they have collectively reached their targets.

The game material in its first prototype consisted of playing cards, a target sheet, energy bricks, and cost bricks. The energy bricks have three properties: Color, width, and height. The width represents the $\mathrm{CO}_{2}$ emissions and the height represents the amount of energy. The color of the individual energy bricks represents the type of energy source. The following energy sources are presented in the game: Hydrogen, solar power, wind power, natural gas, liquid fuels (petrol and diesel), and purchased electricity, which reflects the German energy mix of 2018 [33]. The width of the energy bricks represents the $\mathrm{CO}_{2}$ emissions of the energy source (Table 1).

Table 1. Properties of the energy bricks.

\begin{tabular}{ccccc}
\hline Energy Source & Color & $\mathbf{C O}_{\mathbf{2}}$ Per Brick & Width & Amount of Energy \\
\hline Purchased electricity & Black & $10 \mathrm{t}$ & $10 \mathrm{u}$ & $20,000 \mathrm{kWh}$ \\
Liquid fuels & Red & $5 \mathrm{t}$ & $6 \mathrm{u}$ & $20,000 \mathrm{kWh}$ \\
Natural gas & Beige & $4 \mathrm{t}$ & $4 \mathrm{u}$ & $20,000 \mathrm{kWh}$ \\
Solar power & Yellow & $0 \mathrm{t}$ & $2 \mathrm{u}$ & $20,000 \mathrm{kWh}$ \\
Wind power & White & $0 \mathrm{t}$ & $2 \mathrm{u}$ & $20,000 \mathrm{kWh}$ \\
Hydrogen & Blue & $0 \mathrm{t}$ & $2 \mathrm{u}$ & $20,000 \mathrm{kWh}$ \\
\hline
\end{tabular}

The wider an energy brick is, the more emissions it represents. Hydrogen, solar power, and wind power are considered renewable energies and are therefore $\mathrm{CO}_{2}$-neutral. These two properties of energy bricks 'represent which energy source emits how much $\mathrm{CO}_{2}$. The players learn that renewable energy sources emit negligible amounts of $\mathrm{CO}_{2}$, natural gas emit little, and external electricity emits a lot. The height of the energy bricks represents the amount of energy. Each energy brick has the same height and represents 20,000 kWh of energy. During the game, the energy bricks are built into three energy towers, which cover the sectors of electricity, heating, and transportation in the neighborhood. Playing cards can be used to change the energy towers, as Figure 1 shows. 


\begin{tabular}{|c|c|c|}
\hline Added & Reduced & Replaced by \\
\hline Heating tower & Heating tower & Heating tower \\
\hline
\end{tabular}

(a)

(b)

(c)

Figure 1. Three ways to change the energy towers with the effects of playing cards using the example of the heating tower. (a) Adding energy bricks to the heating tower, (b) removing energy bricks from the heating tower, and (c) replacing energy bricks from the heating tower with energy bricks with different properties.

With these three energy towers, the players learn that energy is supplied to neighborhoods mainly in three sectors and all of them are important for the energy transition. The energy consumption of the neighborhood can be read off the height of the energy towers. The visualization of the otherwise invisible energy creates awareness of energy quantities and the consumption of energy. Such a visualization of energy consumption is a core element of energy feedback [19]. Figure 2 shows a playing card and the final game with some playing cards, the three energy towers, and the cost tower.

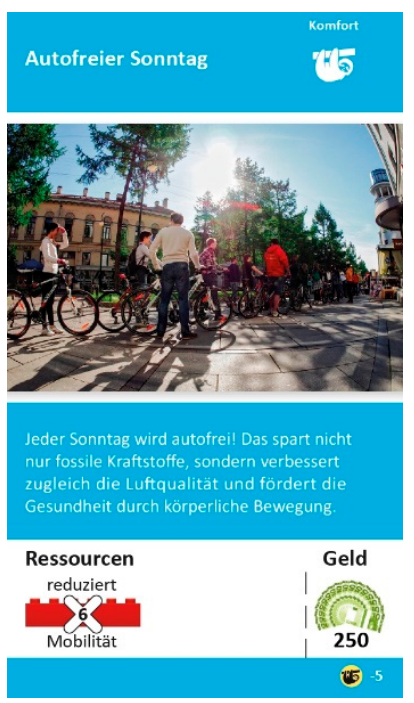

(a)

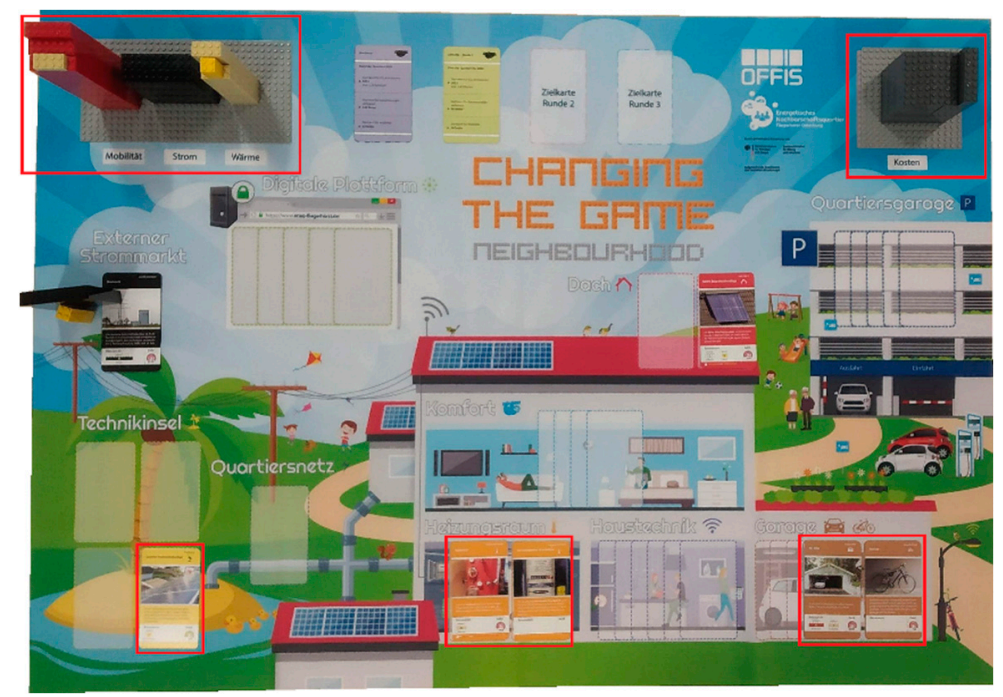

(b)

Figure 2. (a) The playing card "Car-free Sunday" with the text and effects: "Every Sunday is car-free! This not only saves fossil fuels, but also improves air quality and promotes health through physical activity." Effects: Reduces six red fossil fuel bricks from the mobility tower and five small bricks (250€) from the cost tower. (b) The final game with game board, some playing cards (bottom area), the three energy towers (top left), and cost tower (top right).

\subsection{The Game Development Process and Conceptual Phase}

The serious game was developed and tested iteratively and participatively from January 2018 to February 2020 in 15 workshops and game sessions. During the development process, nearly 120 people were involved. The core game development team consisted of three scientists with knowledge in industrial engineering, renewable energies, and computer science. The 117 co-developers 
were end-users and stakeholders with completely different backgrounds. They provide important information and feedback based on their experience and expertise on specific occasions and at specific stages of the development. This method is adaptable in terms of time, location, and number of participants. In addition, it is relatively time-saving for the involved co-designers, as they do not have to learn about game design first to be able to actively participate in the development. We can see a similar approach with the framework "informant design" [34]. In contrast to informant design, we had already started to create game materials in the first phase in order to use them in the first co-design phase.

The development process is structured into four phases:

- Conceptual phase: In the first phase, the learning goals were defined, the concept of the game was designed, and a first prototype was created by the game development team.

- Co-design phases 1-3: In the following three phases, co-designers from different backgrounds were invited to play and modify the game. After and during the phases, the feedback of the co-designers was incorporated into the prototype.

Figure 3 presents a summarizing visualization of the process:

\begin{tabular}{|c|c|c|c|}
\hline \multicolumn{4}{|c|}{ Conceptual phase: Learning goals } \\
\hline \multicolumn{4}{|c|}{$\begin{array}{l}\text { Game development team } \\
\text { defining learning goals: knowledge gain about energy transition, increased awareness of energy issues } \\
\text { prototyping: playing cards, energy and cost bricks, target sheet }\end{array}$} \\
\hline \multicolumn{4}{|c|}{ Co-design phase 1: Content } \\
\hline $\begin{array}{l}\text { Game development } \\
\text { team } \\
\text { prototyping: game board }\end{array}$ & $\begin{array}{l}\text { Industry experts } \\
\text { content: energy system }\end{array}$ & $\begin{array}{l}\text { Scientific experts } \\
\text { content: energy system }\end{array}$ & $\begin{array}{l}\text { Public administration } \\
\text { content: energy-saving } \\
\text { measures }\end{array}$ \\
\hline \multicolumn{4}{|c|}{ Co-design phase 2: Playability } \\
\hline $\begin{array}{l}\text { Game development } \\
\text { team } \\
\text { protot: game mechanics }\end{array}$ & $\begin{array}{l}\text { Game designer } \\
\text { test \& feedback: game } \\
\text { mechanics }\end{array}$ & $\begin{array}{l}\text { Board game players } \\
\text { test \& feedback: game } \\
\text { mechanics }\end{array}$ & $\begin{array}{l}\text { Marketing department } \\
\text { design of game material }\end{array}$ \\
\hline \multicolumn{4}{|c|}{ Co-design phase 3: Usability testing } \\
\hline $\begin{array}{l}\text { Game development } \\
\text { team } \\
\text { prototyping: fine tuning }\end{array}$ & $\begin{array}{l}\text { Citizens \& youngsters } \\
\text { test \& feedback }\end{array}$ & $\begin{array}{l}\text { Industry \& scientific } \\
\text { experts } \\
\text { test \& feedback }\end{array}$ & $\begin{array}{l}\text { Public administration } \\
\text { test \& feedback }\end{array}$ \\
\hline \multicolumn{4}{|c|}{ Final game version } \\
\hline
\end{tabular}

Figure 3. The four phases of game development.

In the first development phase, the learning goals, game format, and target groups were defined. The initial concept of the serious game was designed, and a first, primitive prototype was created by the game development team.

Learning goals: The main learning goal of the new serious game is to impart knowledge about energy transition in general and especially at the neighborhood level. First of all, some basics shall be taught, e.g., that most of the energy used at a neighborhood is consumed in three sectors: Electricity, heat, and transport. It should become clear that for a successful energy transition, all three sectors must be considered and coupled in order to benefit from synergy effects and reduce total system costs [35]. 
In particular, traditional and modern technologies for energy generation, storage, and conversion should be presented and their characteristics explained. A functioning system should always be in the foreground. As renewable energies form the backbone of a sustainable energy transition, they should be a core element of the game. A key characteristic of renewable energies is their fluctuating energy production. The challenges this implies and possible solutions should be highlighted [36]. Classic forms of energy and their effects on the environment are also to be shown. A further learning goal is to raise the players awareness of sustainable use of energy and resources. Therefore, the game should show measures that each individual or the community can take to ensure the success of the energy transition. The game is intended to inspire and motivate people to take a closer look at this topic and possibly adapt their behavior.

Game format and target group: In contrast to a digital computer game or an app, we consciously chose an analogue game. The players should meet live, interact with each other, and learn from each other. The participants should experience the game sessions as an event that will be remembered for a long time and leave a lasting impression.

As a target group we defined adults of all ages who are interested in the topics of energy transition and sustainability, or who are already dealing with them privately or professionally. Additionally, we wanted to address people who enjoy games, like to interact with other people, and want to experience new insights, regardless of whether they are already interested in the field of energy transition and sustainability. In particular, we wanted to address the citizens of Oldenburg in order to involve them in the participation process of the research project $\mathrm{ENaQ}$ and the redesign of the district.

The game was developed with a focus on the energy system of a neighborhood. This will also create a closer connection to the daily life. Since we want to reach a broad audience, only little previous knowledge shall be necessary to play the game. At the same time, it should be appealing for people with more expertise. The playtime should be within a suitable range of a few hours. It should not be too long to discourage potential interested parties from playing. The game should be comfortably playable in an afternoon or evening. On the other hand, the playtime should be long enough to cover the topic in sufficient detail to ensure that the relevant issues are understood and a decent discussion could be initiated.

\section{Results}

This section describes the three co-design phases. It lists how many game sessions were conducted, which stakeholders were involved, and what the focus of each phase was. Additionally, the interactions of the co-designers are described and how their feedback was implemented in the design and game mechanics of the next prototype.

\subsection{Co-Design Phase 1: Content}

The focus in the first co-design phase was on the learning content. This phase consisted of five workshops with experts from science and industry as well as employees from the public administration. These co-designers were part of the ENaQ research consortium. Among the experts were engineers with the special interest of decentralized energy supply and physics scientists. The game development team presented the current game concept. Most of the time, co-designers worked with the game development team to decide which learning content they wanted to convey with the serious game. These experts were necessary to create a realistic and accurate representation of the real world in the game. Scientific and industry experts selected current and modern technologies for energy production, conversion, and storage. They provided data for the energy facilities to be able to represent them correctly in the game. For this purpose, they used example installations of similar sizes. Public administration employees selected energy-saving measures that they considered likely to be feasible in a neighborhood.

Playing cards: In this phase, the co-designers and the game development team selected technologies and measures, which have an impact on energy production and use in the neighborhood. 
These technologies and measures were implemented in 47 playing cards, which were divided into nine categories. Several combinations of playing cards and solutions are possible. By weighing up the advantages and disadvantages of individual technologies and combinations, the players will take a closer look at their effects. Some technologies are dependent on others and need them as a condition to be useful. For example, a power storage unit in a house only makes sense if a photovoltaic system is also available. These dependencies are shown in the game on the according playing cards with a key and lock symbol. Table 2 gives an overview of the playing cards in this phase.

Table 2. Playing card categories and names of the playing cards.

\begin{tabular}{|c|c|c|}
\hline Category & Number of Cards & Names of the Playing Cards \\
\hline Heating room & 5 & $\begin{array}{l}\text { boiler, heat pump, heat exchanger, conventional electricity meter, } \\
\text { smart meter }\end{array}$ \\
\hline Building services & 6 & $\begin{array}{l}\text { electricity storage, LED lighting, more efficient devices, } \\
\text { avoidance of stand-by, energy visualisation, improved } \\
\text { thermal insulation }\end{array}$ \\
\hline Garage & 8 & $\begin{array}{l}\text { one car, second car, }+10 \% \text { electric cars }(3 \times),+10 \% \text { hydrogen cars, } \\
\text { bicycle, e-bike }\end{array}$ \\
\hline Comfort & 4 & $\begin{array}{l}\text { lower indoor temperature, home office, car-free Sunday, holiday } \\
\text { travel by bus/train }\end{array}$ \\
\hline Roof & 5 & $\begin{array}{l}\text { small solar thermal plant, large solar thermal plant, small } \\
\text { photovoltaic plant, large photovoltaic plant, small wind turbine } \\
\text { combined heat and power plant, hydrogen production, }\end{array}$ \\
\hline Technique island & 6 & $\begin{array}{l}\text { hydrogen fuel cell, neighbourhood photovoltaic plant, } \\
\text { neighbourhood battery storage, neighbourhood heat pump }\end{array}$ \\
\hline Local network & 1 & local heating network \\
\hline Digital platform & 5 & $\begin{array}{l}\text { electricity trading, community portal, energy forecast, energy } \\
\text { consulting, dynamic electricity tariffs }\end{array}$ \\
\hline Neighbourhood garage & 6 & $\begin{array}{l}\text { hydrogen car sharing, electric car sharing, neighbourhood cargo } \\
\text { bike, use of public transport, hydrogen bus, e-bike sharing }\end{array}$ \\
\hline External electricity market & 1 & electricity network \\
\hline
\end{tabular}

Game board: In the first workshops, the co-designers realized that it is difficult to have an overview of 47 playing cards. To better weigh the advantages and disadvantages of the playing card combinations and to see the dependencies of the playing cards, the players distributed the playing cards on the table. Since the playing cards lacked a fixed place, they were often picked up, moved, or put aside. After some playing time, it was unclear which cards were played and which were not. To provide an overview, a game board was added as a new element. Now, most of the events of the game take place on the game board. It offers fixed positions for all playing cards, energy towers, and the cost tower. The players can see which playing cards are already in use, how high the energy consumption of the quarter is, and what the target values for the current round are. When a card is played, it can be seen to which spatial area the technology or measure belongs and how the energy consumption or energy supply of the neighborhood changes.

Surplus Energy: A reduction of the greenhouse gas emissions is possible with widespread adoption of distributed generation technologies that use renewable energy sources [37]. Unfortunately, certain technologies, such as photovoltaic plants, generate more electrical energy at certain times than is consumed in the neighborhood at that time. In reality, this energy is fed into the neighboring superordinate electricity grids, which can lead to problems due to electricity penetration in the grid [38]. It is advantageous to consume the decentralized energy locally. This challenge of energy transition is an important learning goal in the serious game. Halverson showed that it is more effective to integrate the learning content into the structure of the game rather than just memorizing it [39]. Hence, we introduced the mechanic of surplus energy bricks. The players are now rewarded for keeping and using temporarily surplus energy in their neighborhood. To do this, the players have various options, such as storing electrical energy in electricity storage systems, using electrical energy in electric vehicles, converting electrical energy into hydrogen, and shifting loads. Thus the game "Changing the Game-Neighbourhood" focuses on the temporal availability of renewable energies. 
Further feedback: Lack of clarity, partly incomprehensible rules, and a too-long playing time were common feedback. The explanation of the rules originally took almost one hour. There were no comparative values to determine realistic target values. This led to long considerations and discussions when agreeing on target values. Some mechanics, such as the deconstruction of playing cards, were not adequately explained in the game manual. An overview of the different energy bricks was missing, which led to frequent questions. Together with the co-designers, possible solutions were developed in the sessions. To that purpose, suggestions were made by the co-designers and discussed in the group, and the advantages and disadvantages were listed and weighed up. As the game was still in an early stage, there were many recommendations to increase the comprehensibility. At the end of each session, the research team had a list of suggestions for improvement. Finally, the research team carefully weighed the suggestions and decided which ones would be implemented in the new prototype. Surprisingly, there was little tension or conflict between the proposals as they were mostly compatible with each other. Some co-designers recommended a color code, others suggested symbols for the categories of playing cards. Some recommended a more understandable wording of the playing cards and playing instructions and others asked for a legend card. Since these suggestions were compatible with each other, most of them were adopted in the next prototypes. Further test sessions in the next phases should show which of these suggestions made a useful change and should be retained and which should be reversed. As a result, a color code and symbols were added for the different categories of playing cards, texts were reworked, and a legend card was created that lists and explains all the energy bricks to improve clarity and comprehensibility. To give comparison values and to shorten the long discussions about the agreement of the target values, three target cards were introduced. The target cards contain fixed target values for three scenarios of different difficulty. The players now only have to choose between these scenarios. The target values were derived from the objectives of the German government for the energy transition [33] and adapted to a neighborhood.

\subsection{Co-Design Phase 2: Playability}

The second phase consisted of two game sessions. The focus of the second phase was on the playability of the game. Among the co-designers in this phase were developers of digital games and serious games from the research consortium, a group of experienced board players who meet regularly, and employees of the marketing department of OFFIS (Institute for Computer Science). All game sessions took place in a similar way. One person from the game development team moderated the game session, explained the rules, and was open to questions. The co-designers played the game with the new prototype. During the game sessions, the game development team took notes and pictures to document the game flow, problems encountered, and new suggestions. Each session ended with a debriefing, which is the core element where game experience is converted into learning [40]. In the group discussions led by the research team, the game experiences were shared and reflected, the learning goals were reviewed, and the session was evaluated. Concluding, the co-designers were asked to give feedback on the game mechanics, the rules, and the game material. After each game session, the game development team critically reviewed the new ideas, and decided whether to implement the changes in the next prototype.

Fun factor: In this phase, we shifted the focus from learning content to playability and fun. The so-called fun factor is a central element of each game, but especially of a serious game [41]. Our experience shows that serious games should not primarily be associated with facts, knowledge, and memorization, as this could scare off potential players. A serious game should be fun in order to address a broad target group. We are convinced that playability is more important than the learning content. Learning is best done as a side-effect. An attractive visual appearance is helpful to increase the fun factor and to make people want to play the serious game at first sight. Serious games should be colorful, attractive, and stimulating; just like a regular game. For this purpose, we involved people from the marketing department from OFFIS to make the design of the game board and playing cards more 
appealing. Like the visual design, entertaining gameplay is just as important to increase playability and should also be considered in this phase.

Comfort coins: In addition to the use of technology, the players can implement energy-saving measures that may limit the comfort of the fictitious quarter inhabitants. For example: A car-free Sunday or the increased use of public transport reduce the consumption of liquid fuels. However, some users regard the temporary abandonment of their car as a restriction of their comfort. In reality, these measures could meet with resistance from part of the population. In the game, players should discuss these measures together, weigh their advantages and disadvantages, and implement the measures that they consider realistic. In fact, some players played all the unpopular measures without hesitation or much discussion just because they were effective in case of energy saving. They took advantage of the fact that these measures had no negative consequences in the game. Other players also felt the imbalance between reality and play in these unpopular measures. According to them, both the positive and negative aspects of unpopular measures should be correctly represented, for example in the form of a comfort scale. An adapted mechanic, the comfort coin, was created for this purpose. Comfort coins are equally distributed among the players. To execute unpopular measures, comfort coins are now used as a currency. The players must first voluntarily collect enough comfort coins together to carry out an unpopular action. There are not enough comfort coins distributed to play all unpopular measures. On the one hand, this mechanic should prevent all comfort reducing playing cards from being used without hesitation. The players should consider which measures offer a greater advantage for the overall system and are feasible. On the other hand, measures that are unpopular for the inhabitants of the neighborhood should also be uncomfortable for the players. The positive and negative effects of these measures are now more realistically presented in the game than in the previous phase. Test games have shown that the introduction of the comfort coins achieves the desired effect. Unpleasant measures are weighed up more carefully and their advantages and disadvantages are discussed before they are implemented. This could be achieved by limiting the possible loss of comfort alone. The effect was further enhanced if a negative effect was exerted on the players when comfort was lost. This can be achieved by offering players a reward for unspent comfort coins at the end of the game. If the comfort coins were spent to use playing cards, the reward was withheld. Candy bars have been found to be effective for this purpose.

Round system: All playing cards were handed out to the players at the beginning of the game. The large amount of playing cards and the resulting possibilities led to negative effects in most test games. Many players felt overwhelmed and stunned by the amount of playing cards. They hesitated long before they put a playing card up for discussion. The gameplay came to a standstill and the fun factor suffered significantly. This example shows that the difficulty level has to be carefully balanced to provide a more enjoyable gaming experience for the players [42]. Ideally, players should be put into a pleasant state of concentration and motivation, which is known as the flow state. According to Csikszentmihalyi [43], the key to achieving the flow state is that the task is neither too difficult nor too easy. The task should correspond approximately to the current skill level of the player. In this phase, it became apparent that the difficulty level was too high and had to be adjusted. Therefore, the co-designers suggested splitting the playing cards over several rounds to avoid overwhelming the players at any time. As a result, three rounds were introduced and the playing cards as well as the comfort coins were allocated to the individual rounds. At the same time, the three target cards with different degrees of difficulty were divided among the three rounds and presented in increasing order of difficulty. In each round, the players should reach new target values in the areas $\mathrm{CO}_{2}$ emissions, total energy consumption, and energy consumption in the transport sector (Table 3). 
Table 3. Starting values and target values of the individual rounds.

\begin{tabular}{ccccc}
\hline \multirow{2}{*}{ Areas } & Start of Game & Round 1 & Round 2 & Round 3 \\
\cline { 2 - 5 } & Starting Values & Target Values & Target Values & Target Values \\
\cline { 2 - 5 } & $\mathbf{2 0 2 0}$ & $\mathbf{2 0 3 0}$ & $\mathbf{2 0 4 0}$ & $\mathbf{2 0 5 0}$ \\
\hline $\mathrm{CO}_{2}$ emissions & $637 \mathrm{t}$ & $391 \mathrm{t}$ & $261 \mathrm{t}$ & $174 \mathrm{t}$ \\
Total energy consumption & 116 bricks & 98 bricks & 84 bricks & 70 bricks \\
Energy consumption transport & 62 bricks & 56 bricks & 49 bricks & 42 bricks \\
\hline
\end{tabular}

The $\mathrm{CO}_{2}$ emissions are calculated from the number of different energy bricks that emit $\mathrm{CO}_{2}$. The total energy consumption is calculated from the number of energy bricks in the sectors electricity, heat, and transport. After each round, the players are rewarded with praise for their achievements. The allocation of the playing cards to the individual rounds was based on several criteria: In any case, all target values should be achievable with the available playing cards and comfort coins. Special attention was paid to the balance of the progressions of play. To avoid overwhelming the players, the choice of possibilities should be limited in the early game [42]. Therefore, the first round mainly includes simpler playing cards. During the rounds, the difficulty increased with stricter target values and a larger selection of more complex playing cards. Ideally, it should be possible to achieve the target values using different solutions, i.e., combinations of cards, especially in the late game. The variety of solutions in the second and third round increases the freedom of decision of the players and the replay value.

\subsection{Co-Design Phase 3: Usability Testing}

The third phase consisted of eight normal game sessions and five short demonstration game sessions. The focus of the third phase was the balance between learning content and playability. Participants in this phase were some of the co-designers from the previous phases, interested citizens from a public game evening event we organized, pupils and teachers at the open day of the University of Oldenburg as well as experts from science and industry from other research projects. Most of the sessions took place in a similar way as in the second phase. In addition to the normal game sessions, we held five short game sessions with groups of students and interviewed two teachers. The pupils were between 16 and 18 years old, attended the 9th to 11th grade of several high schools and did not know the serious game before.

In total, 11 participants were also co-designers from previous phases. We noticed differences between players who were co-designers before and players who did not know the serious game. Players who were previously co-designers were already familiar with some of the game elements and game mechanics, although new elements were added after their work as co-designers. It was easier for them to understand the serious game. Fortunately, most of them held back while playing with people with no previous experience, giving them the chance to get into the game at their own pace without being caught off guard by experienced players. Overall, the co-designers from previous phases were satisfied both with the changes they suggested and with the other changes that were added later.

Stop watch: Some of the game sessions lasted longer than three hours and led to a loss of concentration. This was mainly due to extensive discussions and the indecision of the players. To speed up the game rounds and to increase the dynamic, we introduced a stopwatch as a new element. The playtime was now limited to $30 \mathrm{~min}$ per round. The time limit had a positive effect in most test games. It set a maximum playtime, which is important when planning a game event. It also prevents some game sessions from getting too far into discussions. This increased the dynamics and liveliness during the game. The time pressure was perceived as positive stress. The players were now more motivated to achieve the goals of the individual rounds in the given time and on average made decisions faster. This gain in enjoyment and faster decisions is partly at the expense of the discussions and thus also the learning content, which can now be shorter. Here, it is important to set a healthy balance between 
learning and playability. A time span of between 25 and 30 min per round proved to be a favorable measure, which increases the dynamics of the game and provides enough room for discussion. After the introduction of the stopwatch, the game sessions lasted about two and a half hours. Small breaks between the rounds also helped to maintain the concentration level. In the remaining game sessions, the fine-tuning of the game was done, and last bugs were fixed.

Pupils: Most pupils quickly grasped the mechanics of the game under the guidance of a moderator. After a short training period, they acted independently. The pupils immersed themselves in the serious game, weighed up the advantages and disadvantages of the different playing cards, and were determined to achieve the round goals. They expressed enjoyment of the game, most of them learned some new concepts about the energy transition by their own account, and many could imagine playing it at school. A few pupils found the game mechanics too complex and a few questions remained open for them. The interviewed teachers were concerned that the serious game would take too long for a normal timetable with one and a half hours at most per subject. They could well imagine playing the serious game as a highlight in a project week during which they would prepare the pupils. It remains questionable whether the duration of the serious game does not exceed the concentration period of the pupils or even adults. As pupils were not initially part of the target group, this group was only involved in the development at a late stage. Future serious game projects should involve a group of pupils and teachers earlier in the process to determine whether the serious game is suitable for pupils and account more of their needs.

Number of test sessions: A total of 15 workshops and test sessions were executed. Our experience has shown that the number could be significantly larger to improve further aspects of the game. Even in the most recent test sessions, we received a considerable amount of feedback and added completely new game mechanics such as the stopwatch. On the one hand, the newly added game mechanics need to be evaluated in further test sessions to verify their benefit in practice. On the other hand, the new mechanics influence, intentionally or unintentionally, some of the existing mechanics and characteristics of the game. For example, the stopwatch led to shorter and not as profound discussions as before its implementation. This influence is rarely noticeable in theory alone, but rather often during further test sessions. If a negative influence occurs, it can be balanced by fine tuning the individual mechanics. To stay with the example of the stopwatch, a longer duration of the round allows for more profound discussions. A too-long duration of the round leads to long playtimes and can therefore reduce the fun of the game for many participants. The balancing of all mechanics and their mutual influences can only be evaluated in further test sessions. How many test games with co-designers are necessary probably depends on the type of game and its complexity and still needs to be figured out.

\section{Theoretical Foundations}

As mentioned in the introduction, serious games have been shown to be suitable to bring complex systems closer to citizens and to raise awareness of the topic [6-8]. In addition to the awareness and learning factor, Orduña Alegría et al. [6] also demonstrated that it can serve as a good basis for decision-making and as a communication tool. Therefore, an effective development process is fundamentally important to create a good serious game. Winn describes this process as "creative, and sometimes chaotic" [42]. To give this "chaotic process" a theoretical foundation, we start from three large aspects: (1) Theories about learning and playing as components of serious games, (2) theoretical assumptions about co-design processes, and (3) assumptions of game design by involving stakeholders.

\subsection{Learning + Serious Games}

Play is an essential element of human existence [44]. While playing we discover the environment and learn how to interact with it. The game as a kind of regulated form of playing includes this aspect of discovering and learning: "Play and games are enshrined in our cultural record, emerging with civilizations, always intertwined." [45]. Winn [42] and Zichermann and Cunningham [45] describe that three important factors determine the learning factor of games: Pleasure or flow, reward, 
and progression or time. When properly balanced, the players' motivation increases and the serious game becomes an effective learning tool.

1. Pleasure or flow: The theory of flow is often referred in order to adjust the level of difficulty. This was introduced by Csikszentmihalyi [43] and describes a narrow band of the difficulty level that is neither too hard, which frustrates the players, nor too easy, which bores the players. It depends on the target group but also on the topic of the game. As a result of an iterative, participative game design process, the difficulty level of the game is constantly changing. To reach the so-called flow corridor, play-testing is frequently necessary [42,45].

2. Rewards: Another factor in the process of game balancing is to determine the frequency of rewards. In the course of the game, it is important to reward the learning curve of the players to maintain the motivation to continue playing. This is comparable to a form of operant conditioning $[42,45]$.

3. Progression or time: Equally important is the freedom of action for the players. This is related to the level of difficulty and plays a similar role. A distinction must be made between the complexity of the game mechanics and the complexity through a variety of possible choices in the game. The latter can easily be reduced by limiting the possibilities. Especially at the beginning of a game the choices should be small enough to not overwhelm the players and to guarantee a quick and easy start into the game. At the same time there should be enough possibilities in the course of the game that the game is not perceived as linear. Otherwise, the course and the end seems predictable or even scripted. While the game progresses, new possibilities should be implemented that rely on previously learned skills. The players thus notice their own learning success and this motivates them to continue the game [42,45].

\subsection{Co-Design Process + Participatory}

In co-design or participatory processes, a pool of techniques and methods is used to design workshops in a targeted manner and to ensure that the desired output is achieved. For example, personas, scenario building, or prototypes are used. The needs and requirements of the individual stakeholders in the process should be taken into account [46]. This approach is similar to the design thinking approach, which has become increasingly relevant in recent years. Design thinking was developed on an interdisciplinary basis. The aim is to visualize content, relations, and mechanics to address and further develop these iteratively in workshops with the various stakeholders [47]. Its iterative aspect supports the idea of co-design and prototyping. In addition, the aims for the serious games and the understanding for the target group can be clearly formulated.

Brown and Wyatt [48] describe the design thinking process as "a system of overlapping spaces rather than a sequence of orderly steps." They distinguished the whole process into three spaces: inspiration, ideation, and implementation. "Think of inspiration as the problem or opportunity that motivates the search for solutions; ideation as the process of generating, developing, and testing ideas; and implementation as the path that leads from the project stage into people's lives." [48].

Both approaches have in common that by repeatedly communicating progress and feedback through prototyping and visualization, misunderstandings can be detected early on. This also means that developers can check assumptions about, for example, the comprehensibility of mechanics or the existing prior knowledge of the stakeholder. In this way, so-called developer "blind spots" can also be detected [49].

\subsection{Game Design with Stakeholders}

It has already been shown that not only serious games but also the co-design process to create a serious game is an added value for understanding complex issues [50-52]. Mildner and Mueller [53] show four different ways in which stakeholders can be involved in the game design process (1) as users, (2) as testers, (3) as informants, and (4) as design partners fully incorporated in a co-design process. These levels refer to a hierarchical classification in which the upper level also includes the lower roles 
for the stakeholder $[34,49,53]$. In the informant design framework, stakeholders are consulted as co-designers at different stages of development of a product to provide information and feedback based on their experience and expertise. This framework has the advantages that it is adaptable in terms of time, location, and number of participants and it is less time-consuming for those involved. This is justified by the fact that the stakeholders do not need to know the theoretical background of game design.

According to Winn [42], two other frameworks are particularly important for the development of games with stakeholders. Hunicke et al. [54] presented the mechanics, dynamics, and aesthetics (MDA) framework. It describes the development of a game as a series of changes in mechanics by the developers that affect the aesthetics of the game from the players' point of view via the dynamics. Aesthetics, in this context, means the emotional effect of the game on the players. As an extension, the design, play, and experience (DPE) framework was created to meet the requirements of serious games. The DPE framework represents an iterative process including design, prototyping, game testing, and iteration back to design, with special emphasis on the designer-player relationship and direct feedback. It becomes clear that design, play, and experience are closely related to each other and act as the reinforcing momentum in the development process.

Several case studies showed that the co-design approach can be used to create serious games $[49,52,55,56]$. Nevertheless, further research is needed to make more precise statements about this approach. In particular, a qualitative and quantitative evaluation of the co-design approach and the different frameworks is needed.

\section{Conclusions}

The two challenges: (1) how can a serious game be developed for the energy transition, which keeps a balance between learning and playability, and (2) how can co-design contribute to the development of a serious game, cannot be considered separately. To help answer these questions, an approach to develop a serious game was presented and described in detail using the example of "Changing the Game-Neighbourhood". The four stages of development provide a structure for the development process that proved beneficial in maintaining a balance between learning content and playability. At the beginning, the learning content has to be defined and worked out. In the later stages of development, the focus should shift to playability, to achieve an enjoyable serious game in the end. Therefore, an attractive visual appearance and entertaining gameplay are helpful to increase the fun factor, which is even more important than the learning content.

The influence of all participants of the co-design phases one to three was crucial for the development process of the serious game. The co-designers helped to work out the learning content in the first phases. Industry and scientific experts made an important contribution to the presentation of the different technologies of the energy transition, such as combined heat and power plants and local heat networks. City administration employees provided realistic measures of what each individual or the community can do to save energy. In the later stages of development, the heterogeneous group of co-designers gave useful advice to improve playability and replay value. With their feedback, existing game mechanics were improved and refined, and completely new game elements such as the round system or the comfort coins were added. The use of prototypes, similar to the design thinking model, offered great support in this regard. The prototypes provided initial inspiration, stimulated discussions, and allowed the co-designers to experiment with the game material to discover new features. Co-designers and testers are indispensable especially in the area of balancing the level of difficulty and to give the serious game the final touch. One decisive factor in the development was the diversity of the various stakeholders. This diversity adds various perspectives and ideas, which enriches the serious game on several levels. It is also important to involve end users as co-designers to address their needs early on. Children, teenagers, teachers, students, and lecturers were involved late in this example and should be included earlier, if the serious game is to be used for teaching at schools or universities and to define their needs early on. In future projects, other stakeholders, such as 
environmental associations or energy cooperatives, could also be involved in the development to gain further insights and inspiration. The number of 15 workshops and test sessions could be significantly larger to add new game mechanics, to verify their benefit in practice, and to balance all mechanics and their mutual influences.

The serious game "Changing the Game-Neighbourhood" is a contribution to the Sustainable Development Goal number four "Quality Education". It is intended to impart knowledge about energy transition technologies and measures for saving energy and to promote sustainable lifestyles. During the development process, it has become clear that the energy transition at the neighborhood level is an excellent topic to create a serious game. It can easily be related to the daily life of most people. The amounts of energy are conceivable, the technologies are partly already familiar, and it offers measures of what each individual can do to save energy. After all, every person uses electric devices at home, needs options for transport, and has a need for heating. People, especially the youngest generation, are increasingly interested in a sustainable world, which includes a clean energy supply. Already in the development stage, serious games are suitable as instruments for participation. In the course of the process about 120 stakeholders were involved in 15 workshops. We hope that the developed serious game, and this paper describing its creation, can provide added value for game developers and scientists, and help them develop new serious games. However, future work shall assess the effects of this serious game in terms of imparting knowledge about energy transition and raising awareness of sustainable resource use. In addition, it would be interesting to know which of the unpopular measures are chosen by the players and for what reason. This way, decision makers and others can learn on which measures they may put more emphasis. Further research gaps are the comparison of this approach with existing frameworks and the final answers to the two central questions.

Author Contributions: M.L. and S.W. conceived and designed the research and collected the data; M.L. analyzed the data and wrote the original draft; C.S. and S.W. wrote chapter 4; all authors were involved in reviewing and editing the paper. All authors have read and agreed to the published version of the manuscript.

Funding: This research was funded by the German Federal Ministry of Economics and Energy and the German Federal Ministry of Education and Research under funding No. 03SBE111.

Acknowledgments: The research reported in this paper was undertaken as part of the $\mathrm{ENaQ}$ project: Energetisches Nachbarschaftsquartier-Fliegerhorst Oldenburg. The authors would like to express our gratitude to all participants and to Alexandra Pehlken, Fernando Peñaherrera V., Tobias Brandt and the reviewers for their constructive criticisms and helpful suggestions.

Conflicts of Interest: The authors declare no conflict of interest.

\section{References}

1. Boomsma, C.; Hafner, R.; Pahl, S.; Jones, R.; Fuertes, A. Should We Play Games Where Energy Is Concerned? Perceptions of Serious Gaming as a Technology to Motivate Energy Behaviour Change among Social Housing Residents. Sustainability 2018, 10, 1729. [CrossRef]

2. Orland, B.; Ram, N.; Lang, D.; Houser, K.; Kling, N.; Coccia, M. Saving energy in an office environment: A serious game intervention. Energy Build. 2014, 74, 43-52. [CrossRef]

3. Saitua-Iribar, A.; Corral-Lage, J.; Peña-Miguel, N. Improving Knowledge about the Sustainable Development Goals through a Collaborative Learning Methodology and Serious Game. Sustainability 2020, 12, 6169. [CrossRef]

4. Juan, Y.-K.; Chao, T.-W. Game-Based Learning for Green Building Education. Sustainability 2015, 7, 5592-5608. [CrossRef]

5. Knol, E.; de Vries, P.W. EnerCities, a Serious Game to Stimulate Sustainability and Energy Conservation: Preliminary Results. E-Learn. Pap. 2011, 25, 1-10.

6. Orduña Alegría, M.E.; Schütze, N.; Zipper, S.C. A Serious Board Game to Analyze Socio-Ecological Dynamics towards Collaboration in Agriculture. Sustainability 2020, 12, 5301. [CrossRef] 
7. Eisenack, K. Keep Cool: A Climate Change Board Game for Interdisciplinary Communication and Education. Simul. Gaming 2013, 44, 328-348. [CrossRef]

8. Ampatzidou, C.; Gugerell, K.; Constantinescu, T.; Devisch, O.; Jauschneg, M.; Berger, M. All Work and No Play? Facilitating Serious Games and Gamified Applications in Participatory Urban Planning and Governance. Urban Plan. 2018, 3, 34-46. [CrossRef]

9. Hämäläinen, R. Using a game environment to foster collaborative learning: A design-based study. Technol. Pedagog. Educ. 2011, 20, 61-78. [CrossRef]

10. Bluemink, J.; Hämäläinen, R.; Manninen, T.; Järvelä, S. Group-level analysis on multiplayer game collaboration: How do the individuals shape the group interaction? Interact. Learn. Environ. 2010, 18, 365-383. [CrossRef]

11. Keijser, X.; Ripken, M.; Mayer, I.; Warmelink, H.; Abspoel, L.; Fairgrieve, R.; Paris, C. Stakeholder Engagement in Maritime Spatial Planning: The Efficacy of a Serious Game Approach. Water 2018, 10, 724. [CrossRef]

12. Den Haan, R.-J.; Van der Voort, M.C. On Evaluating Social Learning Outcomes of Serious Games to Collaboratively Address Sustainability Problems: A Literature Review. Sustainability 2018, 10, 4529. [CrossRef]

13. Güney, T. Renewable energy, non-renewable energy and sustainable development. Int. J. Sustain. Dev. World Ecol. 2019, 26, 389-397. [CrossRef]

14. Lund, H. Renewable energy strategies for sustainable development. Energy 2007, 32, 912-919. [CrossRef]

15. Bundesministerium für Umwelt, Naturschutz und nukleare Sicherheit (BMU). Klimaschutzprogramm 2030 der Bundesregierung zur Umsetzung des Klimaschutzplans 2050. Available online: https://www.bundesregierung. de/breg-de/themen/klimaschutz/klimaschutzprogramm-2030-1673578 (accessed on 19 August 2020).

16. Burgess, J.; Nye, M. Re-materialising energy use through transparent monitoring systems. Energy Policy 2008, 36, 4454-4459. [CrossRef]

17. Nolan, J.M.; Schultz, P.W.; Cialdini, R.B.; Goldstein, N.J.; Griskevicius, V. Normative Social Influence is Underdetected. Pers. Soc. Psychol. Bull. 2008, 34, 913-923. [CrossRef] [PubMed]

18. Beyertt, A.; Verwiebe, P.; Seim, S.; Milojkovic, F.; Müller-Kirchenbauer, J. Felduntersuchung zu Behavioral Energy Efficiency Potentialen von privaten Haushalten. 2020. Available online: https://zenodo.org/record/ 3855575\#.X9im8LMRWUk (accessed on 15 December 2020).

19. Vine, D.; Buys, L.; Morris, P. The Effectiveness of Energy Feedback for Conservation and Peak Demand: A Literature Review. OJEE 2013, 2, 7-15. [CrossRef]

20. Fortmann, J.; Glanert, F. Human-Centered Design in the Energy Turnaround Project Enera-It Pays to Go Off the Beaten Track! i-com 2019, 18, 93-100. [CrossRef]

21. Wehkamp, S.; Schmeling, L.; Vorspel, L.; Roelcke, F.; Windmeier, K.-L. District Energy Systems: Challenges and New Tools for Planning and Evaluation. Energies 2020, 13, 2967. [CrossRef]

22. Schmeling, L.; Schönfeldt, P.; Klement, P.; Wehkamp, S.; Hanke, B.; Agert, C. Development of a DecisionMaking Framework for Distributed Energy Systems in a German District. Energies 2020, 13, 552. [CrossRef]

23. Schweizer, P.-J.; Renn, O.; Köck, W.; Bovet, J.; Benighaus, C.; Scheel, O.; Schröter, R. Public participation for infrastructure planning in the context of the German “Energiewende. " Util. Policy 2016, 43, 206-209. [CrossRef]

24. United Nations General Assembly. Sustainable Development Goals. Available online: https://www.un.org/ sustainabledevelopment/sustainable-development-goals/ (accessed on 18 August 2020).

25. ENaQ project homepage. Changing the Game-Neighbourhood Edition-Lernspiel über die Energiewende in Quartieren. Available online: https://www.enaq-fliegerhorst.de/produkt/changingthegame/ (accessed on 23 November 2020).

26. Fijnheer, J.; Oostendorp, H. Steps to Design a Household Energy Game. Int. J. Serious Games $2016,3$. [CrossRef]

27. Hedin, B.; Lundström, A.; Westlund, M.; Markström, E. The Energy Piggy Bank-A Serious Game for Energy Conservation. In Proceedings of the Sustainable Internet and ICT for Sustainability, Funchal, Portugal, 6-7 December 2017.

28. Johnson, D.; Horton, E.; Mulcahy, R.; Foth, M. Gamification and serious games within the domain of domestic energy consumption: A systematic review. Renew. Sustain. Energy Rev. 2017, 73, 249-264. [CrossRef]

29. Energy Crossroads Denmark. Changing the Game. Available online: http://www.energycrossroads.org/ project/changingthegame/ (accessed on 19 August 2020).

30. Castronova, E.; Knowles, I. A Model of Climate Policy Using Board Game Mechanics. IJSG 2015, 2. [CrossRef] 
31. Abad, J.; Booth, L.; Baills, A.; Fleming, K.; Leone, M.; Schueller, L.; Petrovic, B. Assessing policy preferences amongst climate change adaptation and disaster risk reduction stakeholders using serious gaming. Int. J. Disaster Risk Reduct. 2020, 51, 101782. [CrossRef]

32. Onencan, A.; Van de Walle, B.; Enserink, B.; Chelang'a, J.; Kulei, F. WeShareIt Game: Strategic Foresight for Climate-change Induced Disaster Risk Reduction. Procedia Eng. 2016, 159, 307-315. [CrossRef]

33. Bundesministerium für Wirtschaft und Energie (BMWi). Sechster Monitoring-Bericht "Energie der Zukunft". Available online: https://www.bmwi.de/Redaktion/DE/Publikationen/Energie/sechster-monitoring-berichtzur-energiewende.html (accessed on 19 November 2020).

34. Scaife, M.; Rogers, Y.; Aldrich, F.; Davies, M. Designing for or designing with? Informant design for interactive learning environments. In Paper presented at the ACM SIGCHI Conference on Human factors in computing systems, Atlanta, Georgia, March 1997; ACM Press: New York, NY, USA, 1997; pp. 343-350. [CrossRef]

35. Brown, T.; Schlachtberger, D.; Kies, A.; Schramm, S.; Greiner, M. Synergies of sector coupling and transmission reinforcement in a cost-optimised, highly renewable European energy system. Energy 2018, 160, 720-739. [CrossRef]

36. Liang, X. Emerging Power Quality Challenges Due to Integration of Renewable Energy Sources. IEEE Trans. Ind. Appl. 2017, 53, 855-866. [CrossRef]

37. Akorede, M.F.; Hizam, H.; Pouresmaeil, E. Distributed energy resources and benefits to the environment. Renew. Sustain. Energy Rev. 2010, 14, 724-734. [CrossRef]

38. Canova, A.; Giaccone, L.; Spertino, F.; Tartaglia, M. Electrical Impact of Photovoltaic Plant in Distributed Network. IEEE Trans. Ind. Appl. 2009, 45, 341-347. [CrossRef]

39. Halverson, R. What can K-12 school leaders learn from video games and gaming? Innov. J. Online Educ. 2005, 1, 3 .

40. Crookall, D. Serious Games, Debriefing, and Simulation/Gaming as a Discipline. Simul. Gaming 2011, 41. [CrossRef]

41. Ritterfeld, U.; Cody, M.; Vorderer, P. Serious Games: Mechanisms and Effects; Routledge: London, UK; New York, NY, USA, 2009; ISBN 978-1-135-84891-0.

42. Winn, B.M. The design, play, and experience framework. In Handbook of Research on Effective Electronic Gaming in Education; IGI Global: Hershey, PA, USA, 2009; pp. 1010-1024.

43. Csikszentmihalyi, M. Flow: The Psychology of Optimal Experience; Harper \& Row: New York, NY, USA, 1990.

44. Fink, E.; Saine, U.; Saine, T. The Oasis of Happiness: Toward an Ontology of Play. Yale Fr. Stud. 1968, 19-30. [CrossRef]

45. Zichermann, G.; Cunningham, C. Gamification by Design_Implementing Game Mechanics in Web and Mobile Apps, 1st ed.; O’Reilly Media: Sebastopol, CA, USA, 2011.

46. Robertson, T.; Simonsen, J. Challenges and Opportunities in Contemporary Participatory Design. Des. Issues 2012, 28, 3-9. [CrossRef]

47. Meinel, C.; Leifer, L. Design Thinking Research. In Design Thinking Research; Plattner, H., Meinel, C., Leifer, L., Eds.; Springer: Berlin/Heidelberg, Germany, 2012; pp. 1-10. ISBN 978-3-642-31990-7.

48. Brown, T.; Wyatt, J. Design Thinking for Social Innovation. Dev. Outreach 2010, 12, 29-43. [CrossRef]

49. Ampatzidou, C.; Gugerell, K. Participatory game prototyping-Balancing domain content and playability in a serious game design for the energy transition. CoDesign 2019, 15, 345-360. [CrossRef]

50. Frayling, C. Research in Art and Design; Royal College of Art: London, UK, 1993; ISBN 978-1-874175-55-1.

51. Stappers, P.J. Doing Design as a Part of Doing Research. In Design Research Now; Michel, R., Ed.; Birkhäuser: Basel, Switzerland, 2007; pp. 81-91. ISBN 978-3-7643-8471-5.

52. Gugerell, K.; Zuidema, C. Gaming for the energy transition. Experimenting and learning in co-designing a serious game prototype. J. Clean. Prod. 2017, 169, 105-116. [CrossRef]

53. Mildner, P.; Mueller, F. 'Floyd' Design of Serious Games. In Serious Games; Dörner, R., Göbel, S., Effelsberg, W., Wiemeyer, J., Eds.; Springer International Publishing: Cham, Switzerland, 2016; pp. 57-82. ISBN 978-3-319-40611-4.

54. Hunicke, R.; Leblanc, M.; Zubek, R. MDA: A Formal Approach to Game Design and Game Research. In Proceedings of the AAAI Workshop on Challenges in Game AI Workshop, Nineteenth National Conference on Artificial Intelligence, San Jose, CA, USA, 25-26 July 2004. 
55. Ampatzidou, C.; Gugerell, K. Mapping Game Mechanics for Learning in a Serious Game for the Energy Transition. Int. J. E-Plan. Res. 2019, 8,1-23. [CrossRef]

56. De Jans, S.; Van Geit, K.; Cauberghe, V.; Hudders, L.; De Veirman, M. Using games to raise awareness: How to co-design serious mini-games? Comput. Educ. 2017, 110, 77-87. [CrossRef]

Publisher's Note: MDPI stays neutral with regard to jurisdictional claims in published maps and institutional affiliations.

(C) 2020 by the authors. Licensee MDPI, Basel, Switzerland. This article is an open access article distributed under the terms and conditions of the Creative Commons Attribution (CC BY) license (http://creativecommons.org/licenses/by/4.0/). 